\title{
The Effect of Ca on the Reduction of CaO Doped FeO by Carbon
}

\author{
N.Ishikawa*, T.Ogiwara**, M.Takeguchi*, Y.Oba*** and T.Inami*** \\ *Advanced Nano Characterization Center, National Institute for Materials Science (NIMS), 3-13, \\ Sakura, Tsukuba, Ibaraki 305-0003 Japan \\ **Materials Analysis Station National Institute for Materials Science(NIMS), 1-2-1,Sengen, T \\ Tsukuba, Ibaraki 305-0003 Japan \\ ***Faculty of Engineering, Ibaraki University, 4-12-1, Nakanarusawa-cho, Hitachi 316-8511 \\ Japan
}

We developed the in-situ TEM observation during the reduction of iron-oxides by solid carbon applying the deposition of carbon.[1,2]. Wustite(FeO) has attracted much attention because it is one of the intermediate product during the reduction of iron ore. The researches of effects of foreign oxides on the reduction of $\mathrm{FeO}$ were also carried out. $\mathrm{CaO}$ is very important material as foreign oxide because it is reported $\mathrm{CaO}$ promotes the reduction rate of iron oxides.[3,4] But our experiments often showed the different results in using $\mathrm{CaO}$ doped FeO. The different experimental results of bulk and TEM specimens sometimes occurred due to the size of the samples. Our purpose is to investigate the effects of $\mathrm{CaO}$ dynamically in TEM.

The preparation of the specimen is most important in this study. The samples of $\mathrm{CaO}$ doped $\mathrm{FeO}$ were cut by means of diamond sawing with the size of $1 \times 2 \mathrm{~mm}$ square and polished to attain the thickness of less than $100 \mu \mathrm{m}$. The clean surface of $\mathrm{FeO}$ is necessary to contact with solid carbon. But it is extremely difficult to clear away the surface contamination completely. Then the specimens were broken to appear the fracture surface and removed to the deposition apparatus as soon as possible after breaking off to keep the fracture surface clean. The carbon was deposited on the fracture surface with the thickness of $0.5-1 \mu \mathrm{m}$. Final thinning was carried out using FIB to get the thin area locally. The in-situ experiments at elevated temperatures were carried out in the JEM-2000FX. EDS and EELS which installed in JEM-2100F and JEM-3000F respectively were also used for analysis of the component

Figure. 1 shows bright field images of continuous observation of the structural change at the boundary between $\mathrm{FeO}$ which contains $6.0 \mathrm{wt} \% \mathrm{CaO}$ and carbon during keeping at $998 \mathrm{~K}$ up to $25 \mathrm{~min}$, a) before heating and after 5 minutes in b) and after 25 minutes in c). The precipitates were generated and grew into both side of boundary during heating. The reduction start under $773 \mathrm{~K}$ in case of using pure $\mathrm{FeO}$ and $\mathrm{Ca}$ drew up the reduction temperature as the result. EDS indicated the enrichment of $\mathrm{Ca}$ near the edge of $\mathrm{FeO}$ after heating. Maximum concentration of $\mathrm{Ca}$ was approximately ten times higher than before heating. EELS was used to confirm these results. Figure.2 is the GIF mapping of the $\mathrm{Fe} \mathrm{Ca}$ and $\mathrm{O}$ near the edge of $\mathrm{FeO}$. The mapping also showed that enrichment of $\mathrm{Ca}$ near the edge of $\mathrm{FeO}$. Fe precipitated outside the $\mathrm{Ca}$ enriched area. These results indicated that the movement of $\mathrm{Ca}$ to the edge occurred and reduction temperature went up. 


\section{REFERENCES}

[1] N.Ishikawa, K.Furuya, N.Mitsuoka and T.Inami : ISIJ Int. 46 (2006), 1106

[2] N.Ishikawa, K.Furuya, T.Aoyagi, N.Mitsuoka and T.Inami: Tetsu to Hagane, 192(2006), 48.

[3] Y Iguchi, K.Goto and S.Hayashi. Metal. Trans., B 25B(1994), 405

[4] Y.Dai, X.Guo, and J.Zhang, Steel Research Int., 77(2006), 537

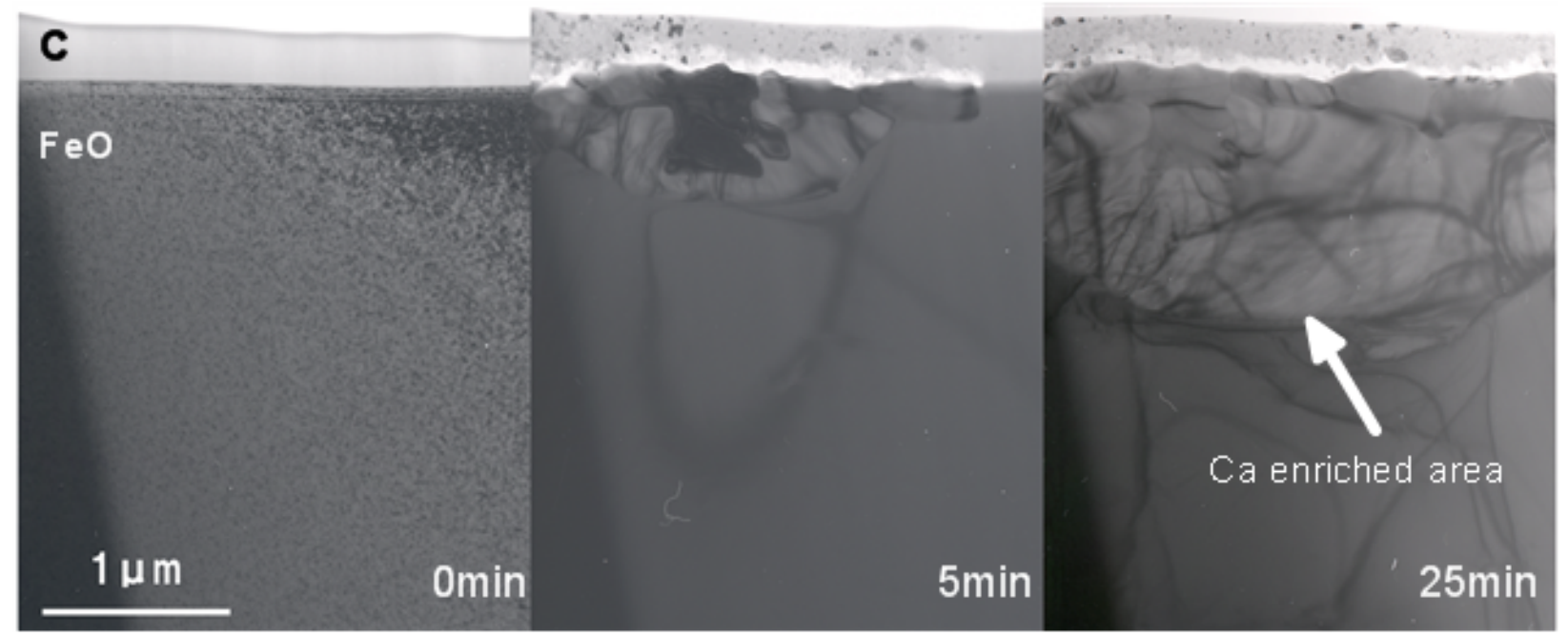

Fig.1. TEM photograph of the change of boundary between $\mathrm{FeO}$ containing $6.0 \mathrm{wt} \% \mathrm{CaO}$ and carbon kept at $998 \mathrm{~K}$ up to $25 \mathrm{~min}$. Ca enriched grain is pointed by an arrow.

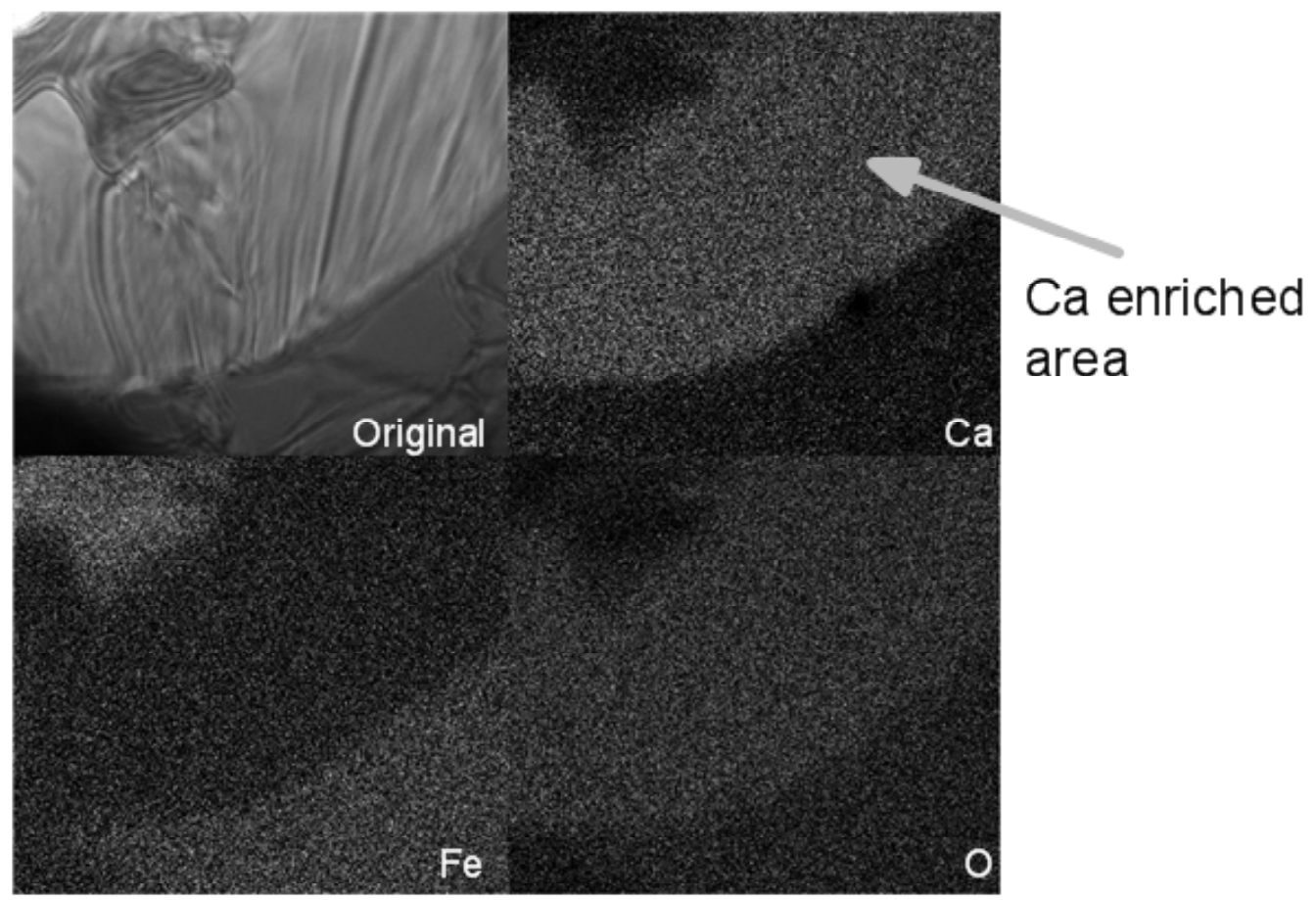

Fig.2. GIF mapping around the precipitate. 